\title{
Predictive factors associated with driving under the influence among Brazilian drug-using drivers
}

\author{
Juliana N. Scherer*, Daiane Silvello, Vanessa L. Volpato, Vinícius S. Roglio, Letícia Fara, \\ Felipe Ornell, Lisia von Diemen, Felix Paim Kessler, Flavio Pechansky \\ Center for Drug and Alcohol Research, Hospital de Clínicas de Porto Alegre, Rua Professor Álvaro Alvim, 400, 90420-020, Porto Alegre, RS, Brazil
}

\section{A R T I C L E I N F O}

\section{Keywords:}

Interpersonal violence

Driving under the influence of psychoactive substances

Childhood trauma

Impulsivity

Personality traits

\begin{abstract}
A B S T R A C T
The incidence of driving under the influence of psychoactive substances (DUI) and its recidivism can be curtailed by the proper identification of specific and predictive characteristics among drug users. In this sense, interpersonal violence (IV), psychiatric comorbidity and impulsivity seem to play an important role in DUI engagement according to previous studies. There are, however, limited data originated from low and middle income countries. In the present study, drug-using Brazilian drivers reporting DUI $(n=75)$ presented a higher prevalence of bipolar disorders (BD; DUI: $8 \%$ vs. non-DUI: $0 \%, \mathrm{p}<0.001$ ), lower prevalence of obsessivecompulsive disorder (OCD; DUI: $0 \%$ vs. non-DUI: $12.6 \%, \mathrm{p}<0.001$ ), and higher prevalence of childhood trauma (DUI: $65.3 \%$ vs. non-DUI: $46.8 \%, \mathrm{p}=0.022)$ than those not reporting DUI $(\mathrm{n}=79)$. The evaluation of impulsivity though the Barratt Impulsivity Scale, which give impulsivity scores ranging from 30 to 120 , showed higher impulsivity scores in the DUI group $(80.4 \pm 8)$ than in the non-DUI group $(77.2 \pm 10, \mathrm{p}=0.045)$. In general, subjects were young adults (mean age of $36 \pm 9$ years), Caucasians (58.4\%), not married (61.0\%), and with elementary schooling (40.3\%) with no significant differences in demographic characteristics between drivers with and without DUI behavior. A multiple Poisson regression model showed that individuals reporting IV as perpetrators and history of childhood trauma were more likely to report DUI (PR: $1.66,95 \%$ CI $1.22-2.7$; PR: 1.57, 95\%CI 1.02-2.42, respectively). The overlapping of violent situations (childhood trauma, IV and DUI) in some individuals presented here corroborates literature data suggesting that DUI can be an externalizing expression of a range of risky behavior, such as impulsiveness and aggressiveness. Moreover, while BD and higher impulsivity scores seem to act as risk factors for DUI, OCD was shown as a protective factor. These results corroborate the hypothesis that individuals with high risk for DUI could probably be identified by multidimensional assessment of cognitive, risky taking, and personality traits, which perhaps could facilitate the development of focused interventions.
\end{abstract}

\section{Introduction}

Traffic crashes (TCs) and interpersonal violence (IV) are among the main external causes of death in Brazil, affecting mostly young men (Malta et al., 2017). Interestingly, both behaviors can be strongly associated with the impairment caused by psychoactive substance use. In fact, data suggest that approximately $10-44 \%$ of TC and $25-50 \%$ of IV occur with individuals under the effect of psychoactive substances (PAS) worldwide, including alcohol, illicit drugs, and medications that affect the central nervous system (Bennett and Bland, 2008; Verstraete and Legrand, 2014). In this sense, national and international studies have reported that drug users are prone to this kind of risky behaviors, not only because of lack of control of drug use, but also because of their high levels of impulsivity and impairment in cognitive functions such as planning and decision making processes (Macdonald et al., 2003; Scherer et al., 2016a, 2016b; Sloan et al., 2014; Stoduto et al., 2011).

Recent data suggest that individuals who engage in risk-taking behaviors, such as driving under the influence of PAS (DUI) and IV, can be characterized by specific features in their personality and cognitive functions (Brown et al., 2016; Van Dorn et al., 2012). As a matter of fact, more far-reaching than drug abuse per se, Brown et al. (2009) have suggested that neurocognitive and psychobiological individual signatures could be better predictors of DUI behavior, allowing for the identification of a cluster of individuals that could probably manifest more than one violent and/or risk-taking behavior during their lifetimes. In this sense, Brazilian studies with drug users have shown

\footnotetext{
* Corresponding author.

E-mail address: jscherer@hcpa.edu.br (J.N. Scherer).
} 
associations of levels of impulsivity, childhood trauma, certain psychiatric comorbidities with criminal involvement/violent behaviors (Diehl et al., 2016; Kessler et al., 2012a, 2012b; Krawczyk et al., 2015), but very little data have been published about the possible association between these variables and DUI engagement in developing countries.

Finding characteristics that could predict DUI involvement among drug users is important in order to guide interventions that could curtail the incidence of DUI occurrence and recidivism, and prevention of TC. So far, the most evaluated characteristics found to predict DUI internationally were alcohol-related behaviors, especially binge drinking, low risk perception, antisocial attitudes, impulsivity, personality traits, psychiatric symptoms, and socioeconomic profile (Bingham et al., 2008; Caetano et al., 2013; Jornet-Gibert et al., 2013; Karjalainen et al., 2011; Pogue et al., 2017; Scheier et al., 2008; Schell et al., 2006; Wickens et al., 2016). However, even with the intense progress being made in developed countries in order to identify clusters of DUI predictors, very little data from low and middle income countries (LAMIC), such as Brazil, are available (Pechansky et al., 2012; Peltzer and Pengpid, 2015; Stewart et al., 2012). As a consequence of the lack of information, there is almost no target public policy interventions, and therefore very little changes in traffic statistics were achieved by developing countries in the last decade. In this study, we aimed at evaluating whether sociodemographic characteristics, impulsivity scores, childhood trauma and psychiatric comorbidities are associated with DUI involvement in a clinical sample of Brazilian drug-using drivers. We also verified the magnitude of co-occurrence of DUI and other risktaking behaviors, particularly IV involvement.

\section{Methods}

\subsection{Sample selection and procedures}

This is a secondary data analysis of a cross-sectional study that consecutively recruited 650 individuals diagnosed with psychoactive substance use disorders according to criteria of DSM IV from a male inpatient treatment center, between the periods of January 2012 to October 2016 (study conducted by the same authors; for other studies using this sample, please see Scherer et al., 2016a,b). This recruitment center is a specialized public service for male voluntary inpatient treatment for substance abuse, and it is connected to a large outpatient unit. Most patients come from other public health services from Porto Alegre, which is the capital of the southernmost state in Brazil. All patients who are admitted in the therapeutic program must fulfil criteria for at least one substance use disorder; if any other health condition is verified during admission, including comorbid psychiatric disorders, they also receive assistance for it with psychotherapy and medication, if necessary. No patient was hospitalized for reasons related to DUI; the main aim of the inpatient treatment was detoxification and recovery of drug dependence

Highly trained staff provides care in the treatment facility, and they receive continued training. The senior group, comprised mainly by psychiatrists, coordinates all professionals (nurses, psychologists, social workers, physical activity professional, and others) who are responsible for adapting, testing and executing appropriate techniques as Relapse Prevention, Contingency Management and Motivation Interview besides other cognitive behavioral strategies and group therapies.

For the main study, inclusion criteria were (1) having a diagnosis of drug use disorder according to DSM IV; (2) being 18yrs. old or older; (3) agreeing to participate in the study. Individuals were excluded from the main study only if they were considered clinically and intellectually unable to participate and/or to understand their participation in the research - which included having symptoms of abstinence (delirium tremens, Wernicke korsakoff, psychosis), dementia and/or mental retardation. The clinical and mental-health assessments were performed by a psychiatrist and a mental health nurse from the treatment facility care team as part of the admission treatment protocol. For the present secondary analysis, we considered only individuals that reported being drivers, yielding a sample of 154 individuals. The classification of being a driver was performed using the question E7 from the $6^{\text {th }}$ version of the Addiction Severity Index instrument (ASI-6): "Do you use or have an automobile?", which was previously used by the authors (Scherer et al., 2016a,b) to classify a similar population of drug users in drivers and non-drivers.

All subjects that present the criteria for study participation were individually approached by trained interviewers and received a detailed explanation of the participation in the research. When subjects agreed to participate, they were interviewed between the fifth and seventh day of detoxification by undergraduate students trained for the application of all instruments and weekly supervised by senior researchers.

The study was approved by the Institutional Review Board and Ethics Committee of Hospital de Clínicas de Porto Alegre under the number 14-0687. All subjects signed informed consents following the guidelines of the IRB.

\subsection{Instruments and measures}

\subsubsection{Sociodemographic and drug use variables}

Demographic characteristics (age, race, marital status, educational level, and year of education) and drug use variables were assessed through the Addiction Severity Index, 6th version (Kessler et al., 2012a,b). Education status was classified as none (no formal education); elementary school (grades 1-8); high school (grades 9-11), and college (undergrad and graduate studies). For marital status, we considered as single all subjects who were not married or living as married. Drug use in the last 30 days was considered as a dichotomous variable (yes/no).

\subsubsection{Psychiatric comorbidities}

Psychiatric comorbidities were evaluated through the Structured Clinical Interview for DSM-IV (SCID-I) (Del-Ben et al., 2001). The SCID I consists of a questionnaire containing the existing symptoms in mental disorder frames categorized in the DSM-IV. In this study, we evaluated the diagnoses of depression, generalized anxiety, post-traumatic stress disorder, social phobia, and bipolar disorder type I (characterized by episodes of severe mania and often depression) and type II (characterized by symptoms of depression and hypomania - milder state of euphoria), using the DSM-IV diagnostic criteria for each comorbidity.

\subsubsection{Impulsivity levels}

Impulsivity scores were obtained from the Barratt Impulsivity Scale (BIS) (Malloy-Diniz et al., 2010). The BIS is a self-report scale composed of 30 items classified using a Likert scale. The total score ranges from 30 to 120 points, with the cut-off value of 68 ( 75 th percentile) indicating a high level of impulsivity. High scores indicate the presence of impulsive behaviors. In addition to a global score, the BIS also analyze partial scores for three subdomains of impulsivity: motor (ranging from 11 to 44 points), attentional (ranging from 11 to 44 points) and non-planning (ranging from 5 to 20 points) impulsiveness (Malloy-Diniz et al., 2015).

\subsubsection{DUI behavior}

DUI was assessed through question L32 of the ASI-6 ("How many days in total did you drive under the influence of drugs or alcohol in the previous six months?"). Those who answered positively for one or more days were considered as belonging to the DUI group, whereas those who reported no involvement were considered in the non-DUI group. The legal conviction for DUI was not assessed in this protocol.

\subsubsection{IV involvement}

history of IV involvement was assessed through questions F11 ("In the last 30 days, did you have any situation with your partner, adult relatives or close friends resulting in pushing/hitting or throwing 
things?"), where individual could be both victim and perpetrator; and L29 A ("How many days in the past six months have you threatened or assaulted someone?") of the ASI-6. Question L29 A, where individual is considered the perpetrator of violence, was dichotomized into yes/no, with those who answered positively for one or more days considered having been threatened or having assaulted someone at least once in the previous six months (yes).

\subsubsection{Childhood trauma}

History of childhood trauma was considered positive if subjects presented at least one of the five trauma categories evaluated through the Child Trauma Questionnaire - CTQ (Grassi-Oliveira et al., 2006). The five categories include physical neglect, emotional neglect, physical abuse, sexual abuse, and emotional abuse.

\subsection{Data analysis}

All data collected for the main study were included in a digital database under the supervision of two project statisticians. After database conclusion, the same statisticians independently reviewed the data, with the aim of improving the quality of information.

Age and impulsivity were the only variables used as quantitative measures in the study, their distribution was verified by histogram and tested by Shapiro-Wilk; in case of symmetric distribution, presented by mean and standard deviation. The categorical variables are presented in absolute and relative frequencies within DUI and non-DUI groups. The prevalence ratio (PR) of DUI between levels of the categorical variables was estimated by simple robust Poisson regression and used as effect size to investigate the associations. In the case of convergence failure of the iterative process of the regression model, the chi-square test was used to investigate the significance of the association. Subsequently, all variables with $\mathrm{p}$-value $<0.1$ in these analyses were used as independent variables in a multiple robust Poisson regression (a generalized linear model set by Poisson distribution, logarithm link and robust variance estimator) to estimate prevalence ratios of DUI controlled for each other.

When more than one quantitative variable is used as independent variable in multiple regression, multicollinearity was investigated by the variance inflation factor (VIF). Analyses were conducted using IBM SPSS software version 18.0 (Armonk, USA) under 95\% confidence level.

\section{Results}

\subsection{Sociodemographic characteristics and drug use profile}

Table 1 summarizes the sociodemographic characteristics and the drug use profile of subjects reporting DUI $(n=75)$ vs. subjects not reporting DUI $(n=79)$. The frequency of DUI behavior among the DUI group presented a median of 15 days, with interquartile interval between 3 and 60 days, in the previous 6 months. In general, subjects were young adults (mean age of $36 \pm 9$ years), Caucasians $(58.4 \%$ ), not married (61.0\%), and with elementary schooling (40.3\%). $26.0 \%$ of the sample reported alcohol as the drug that lead them to treatment, whereas $73.4 \%$ reported crack-cocaine. There were no differences in drug use consumption in the previous 30 days among the two groups.

\subsection{Psychiatric comorbidity, impulsivity and violence among DUI and non- DUI}

There was a higher prevalence of individuals with bipolar disorder (BD) (types I and II) in the DUI group when compared to the non-DUI group ( $8 \%$ vs. $0 \%$; $p<0.001$ ), whereas obsessive-compulsive disorders (OCD) were more prevalent among the non-DUI group (0 vs. 12.6; $\mathrm{p}<0.001$ ) (Table 2). Reporting DUI was associated with higher scores in the total impulsivity analysis $(P R=1.02 ; \mathrm{p}=0.045)$ and more specifically in the attention $(P R=1.07 ; p=0.034)$ and non-
Table 1

Sociodemographic characteristics and drug use profile in a clinical sample of drug-users drivers from Brazil.

\begin{tabular}{|c|c|c|c|c|c|}
\hline Variables & $\begin{array}{l}\text { Total } \\
(\mathrm{n}=154)\end{array}$ & $\begin{array}{l}\text { Non DUI } \\
(\mathrm{n}=79)\end{array}$ & DUI $(n=75)$ & PR & p-value \\
\hline Age $^{2}$ & $36 \pm 9$ & $37 \pm 10$ & $36 \pm 8$ & 0.99 & 0.487 \\
\hline Caucasians ${ }^{1}$ & $90(58.4)$ & $45(57.0)$ & $45(60.0)$ & 1.07 & 0.704 \\
\hline Singles ${ }^{1}$ & $94(61.0)$ & $51(64.6)$ & $43(57.3)$ & 0.86 & 0.352 \\
\hline \multicolumn{6}{|l|}{ Education ${ }^{1}$} \\
\hline ....None & $20(13)$ & $10(12.7)$ & $10(13.3)$ & ref. & ref. \\
\hline ...Elementary school & $62(40.3)$ & $34(43)$ & $28(37.3)$ & 0.90 & 0.699 \\
\hline ...High school & $60(39.0)$ & $29(36.7)$ & $31(41.3)$ & 1.03 & 0.898 \\
\hline ...College & $12(7.8)$ & $6(7.6)$ & $6(8.0)$ & 1.00 & 0.999 \\
\hline $\begin{array}{c}\text { Education: } 12+ \\
\text { years }^{1}\end{array}$ & $24(15.6)$ & 11 (13.9) & $13(17.3)$ & 1.14 & 0.543 \\
\hline \multicolumn{6}{|l|}{$\begin{array}{l}\text { Drug that lead to } \\
\text { treatment }^{1}\end{array}$} \\
\hline ...Alcohol & $40(26.0)$ & $19(24.1)$ & $21(28.0)$ & ref. & ref. \\
\hline $\begin{array}{l}\text {...Cocaine } / \text { crack } \\
\text { cocaine }\end{array}$ & $113(73.4)$ & $59(74.7)$ & $54(72.0)$ & 0.91 & 0.601 \\
\hline ...Opiate & $1(0.6)$ & $1(1.3)$ & $0(0.0)$ & - & - \\
\hline \multicolumn{6}{|l|}{$\begin{array}{l}\text { Drug use in the last } \\
30 \text { days }{ }^{1}\end{array}$} \\
\hline ...Alcohol & $99(64.3)$ & $50(63.3)$ & $49(65.3)$ & 1.05 & 0.793 \\
\hline ...Alcohol in binge & $81(52.6)$ & $39(49.4)$ & $42(56)$ & 1.15 & 0.413 \\
\hline ...Marijuana & $47(30.5)$ & $23(29.1)$ & $24(32)$ & 1.07 & 0.694 \\
\hline ...Cocaine & $64(41.6)$ & $33(41.8)$ & $31(41.3)$ & 0.99 & 0.960 \\
\hline ...Crack-cocaine & $93(60.4)$ & $45(57)$ & $48(64)$ & 1.17 & 0.381 \\
\hline
\end{tabular}

Values expressed by ${ }^{1}$ absolute frequency (\%). ${ }^{2}$ Means \pm Standard Deviation. $\mathrm{PR}=$ prevalence ratio of DUI between categories by simple Poisson regression; The reference categories are indicated by "ref." for categorical variables and was omitted along with the "no" answer for binary variables; the opiate category generates a convergence error, so the poisson regression could not be applied. DUI - Driving Under Influence.

Table 2

Psychiatric comorbidities, impulsivity and risky behaviors among DUI and nonDUI subjects.

\begin{tabular}{|c|c|c|c|c|c|}
\hline Variables & Total & Non DUI & DUI & PR & p-value \\
\hline $\begin{array}{l}\text { ASI6 - } \mathrm{n} \\
\text { Interpersonal violence } \\
\quad \text { IV (last } 6 \text { months) }{ }^{1}\end{array}$ & 154 & 79 & 75 & - & - \\
\hline $\begin{array}{l}\text { Victim/perpetrator } \\
\text { (pushing/hitting/ } \\
\text { throwing things) }\end{array}$ & $32(20.8)$ & $13(16.5)$ & $19(25.3)$ & 1.72 & 0.233 \\
\hline $\begin{array}{l}\text { Perpetrator (threatening/ } \\
\text { assaulting) }\end{array}$ & $25(16.2)$ & $6(7.6)$ & $19(25.3)$ & 3.34 & 0.003 \\
\hline Arrested (lifetime) ${ }^{1}$ & $54(35.1)$ & $32(40.5)$ & $22(29.3)$ & 0.76 & 0.148 \\
\hline Intravenous drug use ${ }^{1}$ & $11(7.1)$ & $7(8.8)$ & $4(5.3)$ & 1.72 & 0.414 \\
\hline BARRAT - n & 137 & 68 & 69 & - & - \\
\hline Total impulsivity ${ }^{2}$ & $78.9 \pm 9$ & $77.2 \pm 10$ & $80.4 \pm 8$ & 1.02 & 0.045 \\
\hline Attentional impulsivity ${ }^{2}$ & $20.6 \pm 3$ & $20.1 \pm 2$ & $21.1 \pm 2$ & 1.07 & 0.034 \\
\hline Motor impulsivity ${ }^{2}$ & $30.7 \pm 4$ & $30.5 \pm 4$ & $31.0 \pm 3$ & 1.02 & 0.447 \\
\hline Planning impulsivity ${ }^{2}$ & $27.4 \pm 5$ & $26.6 \pm 5$ & $28.3 \pm 4$ & 1.04 & 0.031 \\
\hline CTQ - n & 135 & 69 & 66 & - & - \\
\hline Childhood trauma $^{1}$ & $86(55.8)$ & $37(46.8)$ & $49(65.3)$ & 1.64 & 0.022 \\
\hline SCID - n & 121 & 60 & 60 & - & - \\
\hline Depression $^{1}$ & $23(14.9)$ & $12(15.2)$ & $11(14.6)$ & 0.95 & 0.820 \\
\hline $\begin{array}{l}\text { Bipolar disorders (I or } \\
\text { II) }{ }^{1}\end{array}$ & $6(3.9)$ & $0(0.0)$ & $6(8.0)$ & 2.11 & $<0.001$ \\
\hline $\begin{array}{l}\text { Obsessive-compulsive } \\
\text { disorder }{ }^{1 *}\end{array}$ & $10(6.5)$ & $10(12.6)$ & $0(0.0)$ & - & $<0.001$ \\
\hline PTSD $^{1}$ & $10(6.5)$ & $4(5.0)$ & $5(6.6)$ & 1.22 & 0.467 \\
\hline Social Phobia ${ }^{1}$ & $28(18.2)$ & $17(21.5)$ & $11(14.7)$ & 0.75 & 0.248 \\
\hline Generalized anxiety ${ }^{1}$ & $27(17.5)$ & $12(15.2)$ & $15(20.0)$ & 1.18 & 0.429 \\
\hline
\end{tabular}

Values expressed by ${ }^{1}$ absolute frequency (\%). ${ }^{2}$ Means \pm Standard Deviation. $\mathrm{PR}=$ prevalence ratio by simple robust poisson regression, ${ }^{*}$ Chi-Squared test used due to non-convergence of the poisson regression, no PR calculated.

planning ( $P R=1.04 ; \mathrm{p}=0.031)$ subdomains (Table 2 ). There were no differences regarding motor impulsivity among groups.

Regarding IV, a total of $32(20.8 \%)$ individuals reported 


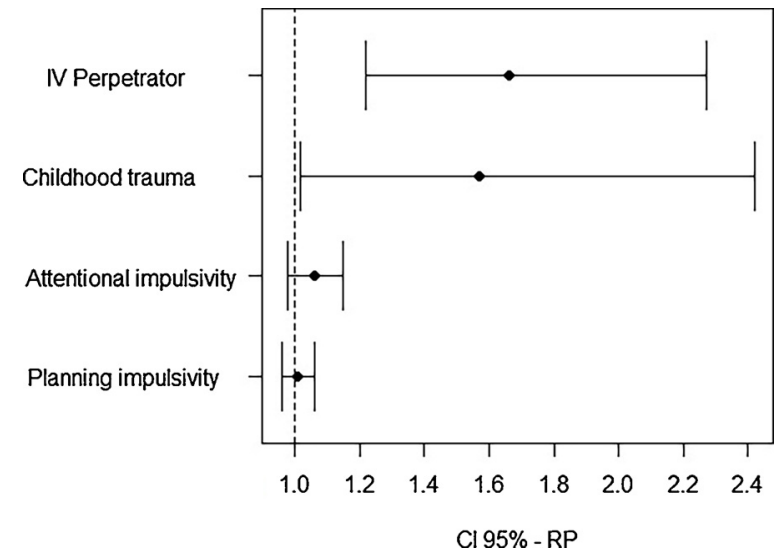

Fig. 1. Robust Multiple Poisson Regression Model for DUI ( $\mathrm{n}=127$ ).

involvement in fights that involved pushing, hitting or throwing things in the previous six months, with no differences among DUI and non-DUI group. On the other hand, when considering the individual as the one threatening, hitting or assaulting someone, the DUI group presented a high prevalence of this behavior $(25.3 \%$ vs. $7.6 \%, \mathrm{p}=0.003)$. This association reveals that the prevalence of DUI is $234 \%$ higher in the group reporting this type of IV behavior ( $R P=3.34 ; p=0.003)$. Other risky behaviors - such as intravenous drug use, presented no differences among groups.

Childhood abuse was reported by 86 (55.8\%) individuals, where individuals reporting DUI presented a higher prevalence of trauma than those not reporting DUI (65.3 vs. $46.8 ; \mathrm{RP}=1.64 ; \mathrm{p}=0.022)$. The prevalence of DUI is $64 \%$ higher in the group reporting childhood abuse. There was no direct association between history of childhood abuse and history of IV (data not shown, $\mathrm{p}=0.951$ ).

\subsection{Multiple Poisson regression model}

The multiple Poisson regression model results are shown in Fig. 1. Individuals with history of IV as a perpetrator and of childhood trauma presented higher prevalence of DUI $(P R=1.66, p=0.001 ; P R=1.57$, $\mathrm{p}=0.040$; respectively). All the other variables were not statistically significant when controlled by each other within the proposed model. Since the total impulsivity is the sum of the three impulsivity subdomains, it was removed from the model to avoid multicollinearity $(\mathrm{VIF}=11.6)$. OCD and Bipolar disorder could not be included in the model due to convergence error and substantial reduction of sample size, respectively.

\section{Discussion}

The association between childhood trauma, drug misuse, and IV has been extensively studied in the last decades, but there are scarce data evaluating potential associations of other factors besides drug misuse with DUI and traffic violations - with almost no data coming from LAMIC. In this sense, our study showed BD as a risk factor for DUI, while OCD was shown as a protective factor - however, due to convergence error, this variable was not included on the final model. Impulsivity, especially in the non-planning and attentional domains, was initially associated with history of DUI, but it had lost significance when incorporated into the model probably because impulsivity could be manifested throughout violent behaviors. Moreover, the multiple Poisson regression showed that history of childhood abuse and history of IV - even when controlled by impulsivity scores, presented higher PRs among the DUI group, suggesting an overlapping of violent situations within some drug-using drivers.

Literature suggests that the DUI population comprises heterogeneous clusters of individuals, especially when it comes to psychiatric comorbidity (Freeman et al., 2011; Karjalainen et al., 2013; LaPlante et al., 2008). In general, individuals with history of DUI present higher prevalence of psychiatric disorders including depression, anxiety, and post-traumatic stress (Faller et al., 2012; Lapham et al., 2006; Pogue et al., 2017). The association of BD and DUI presented here has been already reported in the literature under the hypothesis that during manic and hypomanic states individuals with $\mathrm{BD}$ tend to present impulsive and risk-taking behaviors (Albanese et al., 2010; Freeman et al., 2011). On the other hand, no study so far had focused on the potential role of OCD over risky driving. Based on our results, we suggest that OCD should be further studied as a protective factor for DUI, since this disorder is characterized by patterns of obsessions and/or compulsions, where individuals seek - sometimes in an inefficient way, to exert excessive control over factors that can lead to risky situations for them and/or others. In this way, they might present higher impulsive control than BD patients, and therefore engage in less risky behaviors (Admon et al., 2012; Goodman et al., 2014). This hypothesis is in line with our results that showed that there was no individual with OCD diagnosis in the DUI group - however, due to the small prevalence of OCD and BD found in our sample, further studies should be conducted in order to confirm this evidences.

The impact of impulsivity in risky driving engagement - including DUI, has also been reported in the literature (Bachoo et al., 2013; Brown et al., 2016; Klimkiewicz et al., 2014). Drug users in general are known to present important impulsivity issues (de Wit, 2009; Ryb et al., 2006a) - however, previous studies have already shown that higher impulsivity levels are associated with frequency of risky driving behaviors even among drug dependent individuals (Luk et al., 2017; Pearson et al., 2013), especially for the non-planning and attentional impulsivity subscales (Jakubczyk et al., 2013). In our study, results revealed higher scores in these same subdomains among the DUI group when compared with the non-DUI group. However, the low effect size of these results could be associated with the high levels of impulsivity generally found among drug using individuals, and could also be influenced by the period of detoxification. Since impulsivity is directly associated with the quality of decision-making capacity (Davis et al., 2007; Franken and Muris, 2005), and some data suggest that TCs are more influenced by erratic driver decision making than driving ability, (French et al., 1993), studying these constructs may be fundamental in order to identify clusters of risky drivers. However, it is important to consider that although DUI individuals usually report higher levels of impulsivity than non-DUIs (Luk et al., 2017; Ryb et al., 2006b), it seems that there are no differences in impulsive driving behaviors among the two groups when both groups are evaluated under the effect of alcohol during driving simulations (Van Dyke and Fillmore, 2014). In this sense, interventions against impulsive control could be effective in preventing DUI engagement, but ineffective to prevent risky driving if someone is engaging in DUI.

Another pioneer finding of the present study was the high co-occurrence of both childhood trauma and IV along with DUI, where individuals with childhood trauma and IV were $60 \%$ and $59 \%$ more likely to report DUI in the past six months. These results are in line with previous studies that suggest there is a specific group of DUI individuals - usually the most severe ones, that also present high rates of other criminal offenses, including violence against others (Choi et al., 2015; Nelson et al., 2015). Klimkiewicz et al. (2014) found that almost $30 \%$ of their sample of alcohol users who were arrested for DUI also presented history of fighting under the influence of alcohol. In the same fashion, other studies have also reported an interrelationship between aggressiveness, antisocial traits and risky driving behaviors, including DUI engagement and recidivism (Linn et al., 2016; Wickens et al., 2015). In these same studies, there is also evidence showing that child deviant behaviors are good predictors of risky driving. Taking together, circumstantial evidence makes it seem likely that individuals who engage in high-risk driving are frequently immersed in other behavioral problems as well, being disposed to present high rates of co-occurrence 
with other externalizing issues (e.g. binge drinking, violence against others, and antisocial behavior) (Dotta-Panichi et al., 2013; Shope and Bingham, 2002; Vassallo et al., 2008, 2007).

The influence of childhood trauma in the development of late psychiatric disorders and violent personality had been largely reported (Bruce and Laporte, 2015; Fox et al., 2015; Schimmenti et al., 2015). By the same token, the perpetuation of violent behaviors such as IV and its attenuation through drug misuse among individuals with history of childhood maltreatment has also been shown previously (Brems and Namyniuk, 2002; Glod, 1993; Weaver et al., 2008; World Health Organization - WHO, 2007). Although we did not find a direct association between childhood trauma and IV within our sample, both variables were considered as predictors for DUI in the final model. When evaluating a sample of women with recent history of DUI, Bender et al., (2018) found that more than $60 \%$ of the sample reported alcohol use/abuse in 1 or both parents; and nearly $40 \%$ and $25.5 \%$ of the sample reported sexual assault and physical abuse before age 13, respectively. Lapham et al., (2000) also evaluated physical and sexual abuse in a sample of DUI offenders, finding a prevalence of $10.8 \%$ among men and $12.6 \%$ among women. However, both studies (Bender et al., 2018; Lapham et al., 2000) presented no association between early abuse and DUI recidivism, perhaps due to the low prevalence of childhood trauma within their population. In our study, we observed a high prevalence of childhood trauma, with those reporting childhood trauma being $60 \%$ more likely to report DUI. In this sense, it is possible that childhood abuse, together with drug misuse, could act as a trigger for risky driving behaviors as the same matter as for other externalizing behaviors, which manifest themselves through hyperactivity, impulsiveness, defiant behavior, disobedience, hostility, and aggressiveness (American Psychological Association - APA, 2013).

It is important to consider that this study presents some limitations, including its cross-sectional design - preventing us to state a causal relationship among the variables. In the same fashion, memory bias could have influenced individuals answers, resulting in a distorted estimation of the data reported. Moreover, our study comprises only male subjects, which can influence, as demonstrated in previous studies (Brown et al., 2015), DUI outcome. It is also important to consider that our population comprised only individuals who voluntarily admitted in one public inpatient treatment hospital for drug misuse, with most of them presenting high severity of drug dependence, and therefore they are not a representative sample of Brazilian drug users. Therefore, it would be important to replicate this study in different recruitment centers and with different groups of DUI offenders. However, despite these limitations, our study pioneered in detecting characteristics associated with DUI behavior besides drug misuse in a group of Brazilian drug-drivers.

Even with the increase in alcohol and drug related traffic infractions and collisions around the world, evidence regarding effective interventions to prevent DUI engagement and recidivism are scarce. So far, most of the intervention programs have focused on ignition interlocks, education programs, victim impact panels, Intensive Supervision Programs, and DUI courts - but there are very little data reporting their efficacy (Ferguson, 2012; Miller et al., 2015; Nochajski and Stasiewicz, 2006; Rider et al., 2006). By the other hand, although incipient, studies evaluating interventions targeting drivers with traffic risk taking behaviors and transgressions are showing interesting improvement after cognitive-behavioral treatments (Sommers et al., 2013; Strom et al., 2013; Zinzow and Jeffirs, 2018). For Miller et al. (2015), multicomponent treatment - that arises from its ability to respond to the complexity and combination of legal, social and psychological factors that are associated with DUI behavior - may work best as preventive interventions. Therefore, due to the fact that our sample presented impulsivity and violent history, the authors believe that interventions with focus on impulsivity control, anger management, mindfulness, and decision making improvement could be studied as a new perspective to help reduce DUI, especially among drug users.

\section{Conclusion}

Taking together, our results suggest that childhood abuse and IV, as well as some personality traits, appeared to be particularly important predictors for DUI of PAS. The present study was also able to corroborate data suggesting that risky driving behaviors could be one type of externalizing manifestation among several other behaviors with potential violent outcomes that are present during the lifetime of a specific group of drivers. These results support the hypothesis that there are different clusters of DUI individuals (even when considering drug-using drivers) that perhaps could be identified by multidimensional assessment of personality, risk taking and cognitive traits (Brown et al., 2016; McMillen et al., 1992; Nochajski and Stasiewicz, 2006). It is possible that drug users with history of childhood trauma and IV could be prone to higher odds of recidivism, as previously described in other samples of DUI individuals; however, due to the fact that this was a cross-sectional study, this hypothesis should be addressed by further cohort studies (Choi et al., 2015; Nelson et al., 2015).

\section{Funding}

This work was supported by the Conselho Nacional de Desenvolvimento Científico e Tecnológico (CNPq) and by the Fundo de Incentivo a Pesquisa do Hospital de Clínicas de Porto Alegre (FIPE).

\section{Conflict of interest}

The authors declare no conflict of interest

\section{Acknowledgements}

The authors thank all the subjects who accepted to participate in the present study, as well as the research assistants that collaborated in data collection. We also acknowledge the Conselho Nacional de Desenvolvimento Científico e Tecnológico (CNPq) and the Fundo de Incentivo a Pesquisa do Hospital de Clínicas de Porto Alegre (FIPEHCPA) for providing funding to this research, and the Coordenação de Aperfeiçoamento de Pessoal de Nível Superior (CAPES) for providing scholarships for authors JNS and FO.

\section{References}

Admon, R., Bleich-Cohen, M., Weizmant, R., Poyurovsky, M., Faragian, S., Hendler, T., 2012. Functional and structural neural indices of risk aversion in obsessive-compulsive disorder (OCD). Psychiatry Res. 203 (2-3), 207-213. https://doi.org/10. 1016/j.pscychresns.2012.02.002.

Albanese, M.J., Nelson, S.E., Peller, A.J., Shaffer, H.J., 2010. Bipolar disorder as a risk factor for repeat DUI behavior. J. Affect. Disord. 121 (3), 253-257. https://doi.org/ 10.1016/j.jad.2009.06.015.

American Psychological Association - APA, 2013. Diagnostic and Statistical Manual of Mental Disorders - DSM-5, 5th ed. American Psychiatric Association., Ed., Washington.

Bachoo, S., Bhagwanjee, A., Govender, K., 2013. The influence of anger, impulsivity, sensation seeking and driver attitudes on risky driving behaviour among post-graduate university students in Durban, South Africa. Accid. Anal. Prev. 55, 67-76. https://doi.org/10.1016/j.aap.2013.02.021.

Bender, A.K., Bucholz, K.K., Heath, A.C., McCutcheon, V.V., 2018. Comparison of characteristics of female drivers with single and multiple DUI convictions. Alcohol. Clin. Exp. Res. https://doi.org/10.1111/acer.13590.

Bennett, L., Bland, P., 2008. Substance Abuse and Intimate Partner Violence. https://doi. org/10.1186/1747-597X-1-24.

Bingham, C.R., Shope, J.T., Zhu, J., 2008. Substance-involved driving: predicting driving after using alcohol, marijuana, and other drugs. Traffic Inj. Prev. 9 (6), 515-526. https://doi.org/10.1080/15389580802273698.

Brems, C., Namyniuk, L., 2002. The relationship of chidhood abuse history and substance use in an Alska sample. Subst. Use Misuse 37 (4), 473-494. https://doi.org/10.1081/ JA-120002806.

Brown, T.G., Ouimet, M.C., Nadeau, L., Gianoulakis, C., Lepage, M., Tremblay, J., Dongier, M., 2009. From the brain to bad behaviour and back again: neurocognitive and psychobiological mechanisms of driving while impaired by alcohol. Drug Alcohol Rev. 28 (4), 406-418. https://doi.org/10.1111/j.1465-3362.2009.00053.x.

Brown, T.G., Ouimet, M.C., Nadeau, L., Tremblay, J., Pruessner, J., 2015. Sex differences in the personality and cognitive characteristics of first-time DWI offenders. J. Stud. 
Alcohol Drugs 76 (6), 928-934. Retrieved from. http://www.ncbi.nlm.nih.gov/ pubmed/26562601.

Brown, T.G., Ouimet, M.C., Eldeb, M., Tremblay, J., Vingilis, E., Nadeau, L., Bechara, A., 2016. Personality, executive control, and neurobiological characteristics associated with different forms of risky driving. PLoS One 11 (2), e0150227. https://doi.org/10. 1371/journal.pone.0150227.

Bruce, M., Laporte, D., 2015. Childhood trauma, antisocial personality typologies and recent violent acts among inpatient males with severe mental illness: exploring an explanatory pathway. Schizophr. Res. 162 (1-3), 285-290. https://doi.org/10.1016/ j.schres.2014.12.028.

Caetano, R., Vaeth, P.A.C., Mills, B.A., 2013. Rates and predictors of DUI among U.S.-Mexico border and non-border Mexican Americans. Accid. Anal. Prev. 59, 289-295. https://doi.org/10.1016/j.aap.2013.05.026.

Choi, N.G., DiNitto, D.M., Marti, C.N., 2015. Older adults who are at risk of driving under the influence: a latent class analysis. Psychol. Addict. Behav. 29 (3), 725-732. https://doi.org/10.1037/adb0000055.

Davis, C., Patte, K., Tweed, S., Curtis, C., 2007. Personality traits associated with decisionmaking deficits. Pers. Individ. Dif. 42 (2), 279-290. https://doi.org/10.1016/J.PAID. 2006.07.006.

de Wit, H., 2009. Impulsivity as a determinant and consequence of drug use: a review of underlying processes. Addict. Biol. 14 (1), 22-31. https://doi.org/10.1111/j.13691600.2008.00129.x.

Del-Ben, C.M., Vilela, J.A.A., Crippa, J.A., de, S., Hallak, J.E.C., Labate, C.M., Zuardi, A.W., 2001. Confiabilidade da \&quot;Entrevista Clínica Estruturada para o DSM-IV Versão Clínica\&quot; traduzida para o português. Rev. Bras. Psiquiatr. 23 (3), 156-159. https://doi.org/10.1590/S1516-44462001000300008.

Diehl, A., Pillon, S.C., dos Santos, M.A., Rassool, G.H., Laranjeira, R., 2016. Criminality and sexual behaviours in substance dependents seeking treatment. J. Psychoactive Drugs 48 (2), 124-134. https://doi.org/10.1080/02791072.2016.1168534.

Dotta-Panichi, R.M., Wagner, A., Sarriera, J.C., 2013. Discriminant profile of young adulthood driving behavior among brazilian drivers. Span. J. Psychol. 16, E8. https://doi.org/10.1017/sjp.2013.10.

Faller, S., Webster, J. M., Leukefeld, C. G., Bumaguin, D. B., Duarte, P.D.C.A.V., De Boni, R. \& Pechansky, F. (2012). Psychiatric disorders among individuals who drive after the recent use of alcohol and drugs. Revista Brasileira de Psiquiatria (Sao Paulo, Brazil 1999), 34(3), 314-320. Retrieved from http://www.ncbi.nlm.nih.gov/ pubmed/23429777.

Ferguson, S.A., 2012. Alcohol-impaired driving in the United States: contributors to the problem and effective countermeasures. Traffic Inj. Prev. 13 (5), 427-441. https:// doi.org/10.1080/15389588.2012.656858.

Fox, B.H., Perez, N., Cass, E., Baglivio, M.T., Epps, N., 2015. Trauma changes everything: examining the relationship between adverse childhood experiences and serious, violent and chronic juvenile offenders. Child Abuse Negl. 46, 163-173. https://doi. org /10.1016/j.chiabu.2015.01.011.

Franken, I.H.A., Muris, P., 2005. Individual differences in decision-making. Pers. Individ. Dif. 39 (5), 991-998. https://doi.org/10.1016/J.PAID.2005.04.004.

Freeman, J., Maxwell, J.C., Davey, J., 2011. Unraveling the complexity of driving while intoxicated: a study into the prevalence of psychiatric and substance abuse comorbidity. Accid. Anal. Prev. 43 (1), 34-39. https://doi.org/10.1016/j.aap.2010.06. 004.

French, D.J., West, R.J., Elander, J., Wilding, J.M., 1993. Decision-making style, driving style, and self-reported involvement in road traffic accidents. Ergonomics 36 (6), 627-644. https://doi.org/10.1080/00140139308967925.

Glod, C.A., 1993. Long-term consequences of childhood physical and sexual abuse. Arch. Psychiatr. Nurs. 7 (3), 163-173. https://doi.org/10.1016/0883-9417(93)90043-V.

Goodman, W.K., Grice, D.E., Lapidus, K.A.B., Coffey, B.J., 2014. Obsessive-compulsive disorder. Psychiatr. Clin. North Am. 37 (3), 257-267. https://doi.org/10.1016/j.psc. 2014.06.004.

Grassi-Oliveira, R., Stein, L.M., Pezzi, J.C., 2006. Tradução e validação de conteúdo da versão em português do Childhood Trauma Questionnaire. Rev. Saã ${ }^{\circ}$ de Pãoblica 40 (2), 249-255. https://doi.org/10.1590/S0034-89102006000200010.

Jakubczyk, A., Klimkiewicz, A., Wnorowska, A., Mika, K., Bugaj, M., Podgórska, A., Wojnar, M., 2013. Impulsivity, risky behaviors and accidents in alcohol-dependent patients. Accid. Anal. Prev. 51, 150-155. https://doi.org/10.1016/j.aap.2012.11. 013.

Jornet-Gibert, M., Gallardo-Pujol, D., Suso, C., Andrés-Pueyo, A., 2013. Attitudes do matter: the role of attitudes and personality in DUI offenders. Accid. Anal. Prev. 50, 445-450. https://doi.org/10.1016/j.aap.2012.05.023.

Karjalainen, K., Lintonen, T., Impinen, A., Lillsunde, P., Mäkelä, P., Rahkonen, O., Ostamo, A., 2011. Socio-economic determinants of drugged driving - a register-based study. Addiction 106 (8), 1448-1459. https://doi.org/10.1111/j.1360-0443.2011. 03422.x

Karjalainen, K., Lintonen, T., Joukamaa, M., Lillsunde, P., 2013. Mental disorders associated with driving under the influence of alcohol and/or drugs: a register-based study. Eur. Addict. Res. 19 (3), 113-120. https://doi.org/10.1159/000342569.

Kessler, F., Cacciola, J., Alterman, A., Faller, S., Souza-Formigoni, M. L., Cruz, M. S., Pechansky, F. (2012). Psychometric properties of the sixth version of the Addiction Severity Index (ASI-6) in Brazil. Revista Brasileira de Psiquiatria (São Paulo, Brazil :1999), 34(1), 24-33. Retrieved from http://www.ncbi.nlm.nih.gov/pubmed/ 22392385.

Kessler, F.H.P., Barbosa Terra, M., Faller, S., Ravy Stolf, A., Carolina Peuker, A., Benzano, D., Pechansky, F., 2012b. Crack users show high rates of antisocial personality disorder, engagement in illegal activities and other psychosocial problems. Am. J. Addict. 21 (4), 370-380. https://doi.org/10.1111/j.1521-0391.2012.00245.x.

Klimkiewicz, A., Jakubczyk, A., Wnorowska, A., Klimkiewicz, J., Bohnert, A., Ilgen, M.A., Wojnar, M., 2014. Violent behavior and driving under the influence of alcohol: prevalence and association with impulsivity among individuals in treatment for alcohol dependence in Poland. Eur. Addict. Res. 20 (3), 151-158. https://doi.org/10. $1159 / 000356192$.

Krawczyk, N., Filho, C.L.V., Bastos, F.I., 2015. The interplay between drug-use behaviors, settings, and access to care: a qualitative study exploring attitudes and experiences of crack cocaine users in Rio de Janeiro and São Paulo. Brazil. Harm Reduct. J. 12 (1), 24. https://doi.org/10.1186/s12954-015-0059-9.

Lapham, S.C., Skipper, B.J., Hunt, W.C., Chang, I., 2000. Do risk factors for re-arrest differ for female and male drunk-driving offenders? Alcohol. Clin. Exp. Res. 24 (11), 1647-1655. Retrieved from. http://www.ncbi.nlm.nih.gov/pubmed/11104112.

Lapham, S.C., C'de Baca, J., McMillan, G.P., Lapidus, J., 2006. Psychiatric disorders in a sample of repeat impaired-driving offenders. J. Stud. Alcohol 67 (5), 707-713. Retrieved from. http://www.ncbi.nlm.nih.gov/pubmed/16847539.

LaPlante, D.A., Nelson, S.E., Odegaard, S.S., LaBrie, R.A., Shaffer, H.J., 2008. Substance and psychiatric disorders among men and women repeat driving under the influence offenders who accept a treatment-sentencing option. J. Stud. Alcohol Drugs 69 (2), 209-217. Retrieved from. http://www.ncbi.nlm.nih.gov/pubmed/18299761.

Linn, B.K., Nochajski, T., Wieczorek, W., 2016. Relationship of aggression, negative affect, substance use problems, and childhood delinquency to DWI recidivism. Am. J. Drug Alcohol Abuse 42 (1), 48-55. https://doi.org/10.3109/00952990.2015. 1085541.

Luk, J.W., Trim, R.S., Karyadi, K.A., Curry, I., Hopfer, C.J., Hewitt, J.K., ... Wall, T.L., 2017. Unique and interactive effects of impulsivity facets on reckless driving and driving under the influence in a high-risk young adult sample. Pers. Individ. Dif. 114, 42-47. https://doi.org/10.1016/j.paid.2017.03.048.

Macdonald, S., Anglin-Bodrug, K., Mann, R.E., Erickson, P., Hathaway, A., Chipman, M., Rylett, M., 2003. Injury risk associated with cannabis and cocaine use. Drug Alcohol Depend. 72, 99-115. https://doi.org/10.1016/S0376-8716(03)00202-3.

Malloy-Diniz, L.F., Mattos, P., Leite, W.B., Abreu, N., Coutinho, G., Paula, J., de, J., Fuentes, D., 2010. Tradução e adaptação cultural da Barratt Impulsiveness Scale (BIS11) para aplicação em adultos brasileiros. J. Bras. Psiquiatr. 59 (2), 99-105. https:// doi.org/10.1590/S0047-20852010000200004.

Malloy-Diniz, L.F., Paula, J., de, J., Vasconcelos, A.G., de Almondes, K.M., Pessoa, R., Faria, L., Mattos, P., 2015. Normative data of the Barratt Impulsiveness Scale 11 (BIS 11) for Brazilian adults. Rev. Bras. Psiquiatr. 37 (3), 245-248. https://doi.org/10. 1590/1516-4446-2014-1599.

Malta, D.C., Minayo, M.C., de, S., Filho, Soares, Silva, A.M., da, M.M.A., Montenegro, M., de, M.S., Ladeira, R.M., Naghavi, M., 2017. Mortalidade e anos de vida perdidos por violências interpessoais e autoprovocadas no Brasil e Estados: análise das estimativas do Estudo Carga Global de Doença, 1990 e 2015. Rev. Bras. Epidemiol. 20 (suppl 1), 142-156. https://doi.org/10.1590/1980-5497201700050012.

McMillen, D.L., Adams, M.S., Wells-Parker, E., Pang, M.G., Anderson, B.J., 1992. Personality traits and behaviors of alcohol-impaired drivers: a comparison of first and multiple offenders. Addict. Behav. 17 (5), 407-414. Retrieved from. http://www. ncbi.nlm.nih.gov/pubmed/1442235.

Miller, P.G., Curtis, A., Sønderlund, A., Day, A., Droste, N., 2015. Effectiveness of interventions for convicted DUI offenders in reducing recidivism: a systematic review of the peer-reviewed scientific literature. Am. J. Drug Alcohol Abuse 41 (1), 16-29. https://doi.org/10.3109/00952990.2014.966199.

Nelson, S.E., Belkin, K., LaPlante, D.A., Bosworth, L., Shaffer, H.J., 2015. A prospective study of psychiatric comorbidity and recidivism among repeat DUI offenders. Arch. Sci. Psychol. 3 (1), 8-17. Retrieved from. http://www.ncbi.nlm.nih.gov/pubmed/ 26539339.

Nochajski, T.H., Stasiewicz, P.R., 2006. Relapse to driving under the influence (DUI): a review. Clin. Psychol. Rev. 26 (2), 179-195. https://doi.org/10.1016/j.cpr.2005.11. 006.

Pearson, M.R., Murphy, E.M., Doane, A.N., 2013. Impulsivity-like traits and risky driving behaviors among college students. Accid. Anal. Prev. 53, 142-148. https://doi.org/ 10.1016/j.aap.2013.01.009.

Pechansky, F., Duarte, P.D.C.A.V., De Boni, R., Leukefeld, C. G., von Diemen, L., Bumaguin, D. B, Fuchs, D. F. P. (2012). Predictors of positive Blood Alcohol Concentration (BAC) in a sample of Brazilian drivers. Revista Brasileira de Psiquiatria (Sao Paulo, Brazil: 1999), 34(3), 277-285. Retrieved from http://www.ncbi.nlm.nih. gov/pubmed/23429773.

Peltzer, K., Pengpid, S., 2015. Drinking and driving among university students in 22 low, middle income and emerging economy countries. Iran. J. Public Health 44 (10), 1330-1338. Retrieved from. http://www.ncbi.nlm.nih.gov/pubmed/26576345.

Pogue, Y.Z., Hakes, J.K., Sloan, F.A., 2017. Is major depression linked to alcohol-impaired driving? Subst. Use Misuse 52 (14), 1871-1882. https://doi.org/10.1080/10826084. 2017.1318147.

Rider, R., Kelley-Baker, T., Voas, R.B., Murphy, B., McKnight, A.J., Levings, C., 2006. The impact of a novel educational curriculum for first-time DUI offenders on intermediate outcomes relevant to DUI recidivism. Accid. Anal. Prev. 38 (3), 482-489. https://doi. org/10.1016/j.aap.2005.11.004.

Ryb, G.E., Dischinger, P.C., Kufera, J.A., Read, K.M., 2006a. Risk perception and impulsivity: association with risky behaviors and substance abuse disorders. Accid. Anal. Prev. 38 (3), 567-573. https://doi.org/10.1016/J.AAP.2005.12.001.

Ryb, G.E., Dischinger, P.C., Kufera, J.A., Read, K.M., 2006b. Risk perception and impulsivity: association with risky behaviors and substance abuse disorders. Accid. Anal. Prev. 38 (3), 567-573. https://doi.org/10.1016/j.aap.2005.12.001.

Scheier, L.M., Lapham, S.C., C'de Baca, J., 2008. Cognitive predictors of alcohol involvement and alcohol consumption-related consequences in a sample of drunkdriving offenders. Subst. Use Misuse 43 (14), 2089-2115. https://doi.org/10.1080/ 10826080802345358.

Schell, T.L., Chan, K.S., Morral, A.R., 2006. Predicting DUI recidivism: personality, attitudinal, and behavioral risk factors. Drug Alcohol Depend. 82 (1), 33-40. https://doi. 
org/10.1016/j.drugalcdep.2005.08.006

Scherer, J.N., Schuch, S., Ornell, F., Sordi, A.O., Bristot, G., Pfaffenseller, B., von Diemen, L., 2016a. High levels of brain-derived neurotrophic factor are associated with treatment adherence among crack-cocaine users. Neurosci. Lett. 630, 169-175. https://doi.org/10.1016/j.neulet.2016.07.050.

Scherer, J.N., Silvestrin, R., Ornell, F., Roglio, V., Sousa, T.R.V., Von Diemen, L., Pechansky, F., 2016b. Prevalence of driving under the influence of psychoactive substances and road traffic crashes among Brazilian crack-using drivers. Drug Alcohol Depend. 168, 255-262. https://doi.org/10.1016/j.drugalcdep.2016.09.017.

Schimmenti, A., Di Carlo, G., Passanisi, A., Caretti, V., 2015. Abuse in childhood and psychopathic traits in a sample of violent offenders. Psychol. Trauma 7 (4), 340-347. https://doi.org/10.1037/tra0000023.

Shope, J.T., Bingham, C.R., 2002. Drinking-driving as a component of problem driving and problem behavior in young adults. J. Stud. Alcohol 63 (1), 24-33. Retrieved from. http://www.ncbi.nlm.nih.gov/pubmed/11925055.

Sloan, F.A., Eldred, L.M., Davis, D.V., 2014. Addiction, drinking behavior, and driving under the influence. Subst. Use Misuse 49 (6), 661-676. https://doi.org/10.3109/ 10826084.2013.858167.

Sommers, M.S., Lyons, M.S., Fargo, J.D., Sommers, B.D., McDonald, C.C., Shope, J.T., Fleming, M.F., 2013. Emergency department-based brief intervention to reduce risky driving and hazardous/harmful drinking in young adults: a randomized controlled trial. Alcohol. Clin. Exp. Res. 37 (10), 1753-1762. https://doi.org/10.1111/acer. 12142 .

Stewart, K., Silcock, D., Wegman, F., 2012. Reducing drink driving in low- and middleincome countries: challenges and opportunities. Traffic Inj. Prev. 13 (2), 93-95. https://doi.org/10.1080/15389588.2011.634464.

Stoduto, G., Mann, R.E., Ialomiteanu, A., Wickens, C.M., Brands, B., 2011. Examining the link between collision involvement and cocaine use. Drug Alcohol Depend. 123, 260-263. https://doi.org/10.1016/j.drugalcdep.2011.10.008.

Strom, T., Leskela, J., Possis, E., Thuras, P., Leuty, M.E., Doane, B.M., Rosenzweig, L., 2013. Cognitive-behavioral group treatment for driving-related anger, aggression, and risky driving in combat veterans: a pilot study. J. Trauma. Stress 26 (3), 405-408. https://doi.org/10.1002/jts.21808.

Van Dorn, R., Volavka, J., Johnson, N., 2012. Mental disorder and violence: is there a relationship beyond substance use? Soc. Psychiatry Psychiatr. Epidemiol. 47 (3), 487-503. https://doi.org/10.1007/s00127-011-0356-X.

Van Dyke, N., Fillmore, M.T., 2014. Acute effects of alcohol on inhibitory control and simulated driving in DUI offenders. J. Safety Res. 49 (5), e1-e11. https://doi.org/10. 1016/j.jsr.2014.02.004.

Vassallo, S., Smart, D., Sanson, A., Harrison, W., Harris, A., Cockfield, S., McIntyre, A., 2007. Risky driving among young Australian drivers: trends, precursors and correlates. Accid. Anal. Prev. 39 (3), 444-458. https://doi.org/10.1016/j.aap.2006.04. 011.

Vassallo, S., Smart, D., Sanson, A., Cockfield, S., Harris, A., McIntyre, A., Harrison, W., 2008. Risky driving among young Australian drivers II: co-occurrence with other problem behaviours. Accid. Anal. Prev. 40 (1), 376-386. https://doi.org/10.1016/j. aap.2007.07.004.

Verstraete, A.G., Legrand, S.A., 2014. Drug use, impaired driving and traffic accidents. European Monitoring Centre for Drugs and Drug Addiction (EMCDDA), Lisbon. https://doi.org/10.2810/26821. ISBN: 978-92-9168-687-2.

Weaver, C.M., Borkowski, J.G., Whitman, T.L., 2008. Violence breeds violence: childhood exposure and adolescent conduct problems. J. Commun. Psychol. 36 (1), 96-112. https://doi.org/10.1002/jcop.20219.

Wickens, C.M., Vingilis, E., Mann, R.E., Erickson, P., Toplak, M.E., Kolla, N.J., ... Ilie, G., 2015. The impact of childhood symptoms of conduct disorder on driver aggression in adulthood. Accid. Anal. Prev. 78, 87-93. https://doi.org/10.1016/j.aap.2015.02. 013.

Wickens, C.M., Flam-Zalcman, R., Mann, R.E., Stoduto, G., Docherty, C., Thomas, R.K., 2016. Characteristics and predictors of recidivist drink-drivers. Traffic Inj. Prev. 17 (6), 564-572. https://doi.org/10.1080/15389588.2015.1125477.

World Health Organization - WHO, 2007. The cycles of violence - The relationship between childhood maltreatment and the risk of later becoming a victim or perpetrator of violence. Violence and Injury Prevention Programme, WHO European Centre for Environment and Health, Rome, Copenhagen.

Zinzow, H.M., Jeffirs, S.M., 2018. Driving aggression and anxiety: intersections, assessment, and interventions. J. Clin. Psychol. 74 (1), 43-82. https://doi.org/10.1002/ jclp.22494. 